\title{
Serum Human Epididymis Protein 4 (HE4) in the Differential Diagnosis of Peritoneal Tuberculosis: A Report of Two Cases
}

\author{
Canan Kabaca ${ }^{1}, Z_{\text {Zehra Nihal Dolgun }}{ }^{1}$, Ayşegül Telci², Ateş Karateke ${ }^{1}$ \\ ${ }^{1}$ Department of Gynecologic Oncology, Zeynep Kamil Women and Children's Health and Research Hospital, İstanbul, Turkey \\ ${ }^{2}$ Department of Biochemistry, İstanbul University İstanbul Medicine Faculty, İstanbul, Turkey
}

\section{Dear Editor,}

Peritoneal tuberculosis mimics ovarian cancer due to clinical, radiological and laboratory similarities (1). Patients with peritoneal tuberculosis usually have weight loss, abdominal pain and gastrointestinal symptoms similar to ovarian cancer. Serum cancer antigen 125 (CA-125) rises in almost all cases with tuberculosis (1). Radiologically, ascites is present with an abdominopelvic mass that overlaps late-stage ovarian carcinoma leading to unnecessary laparotomy. Human epididymis protein 4 (HE4) has been shown to be overexpressed by epithelial ovarian cancers (2). It is less likely to be elevated falsely in cases of benign neoplasms, unlike serum CA-125, and can be used for the differential diagnosis of ovarian cancer (3). Here we present two cases of peritoneal tuberculosis whose definitive diagnoses were made in the Gynaecological Oncology Clinic of Zeynep Kamil Women's and Children's Health Education and Research Hospital, İstanbul. The first case was a 22-year-old virgin female who was admitted to hospital with constant pelvic pain for three months. Abdominal ultrasonography revealed a heterogenous, septated and partially solid cystic mass of $120 * 80 \mathrm{~mm}$ that had filled the posterior pelvic cavity. Abdominal magnetic resonance imaging (MRI) revealed an intra-abdominal mass with papillary projections and omental cake formations, in addition to loculated ascitic fluid. Serum CA-125 level was 471 $\mathrm{U} / \mathrm{mL}$ (normal $<25 \mathrm{U} / \mathrm{mL}$ ) while all other markers were within normal limits. HE4 was measured as $4.34 \mathrm{pM}$ (normal < $40 \mathrm{pM}$ ). A peritoneal biopsy was taken by mini-laparatomy and reported necrotizing granulomatous inflammation with Langerhans-type giant cells (tuberculosis). The second case was a 21-year-old virgin girl who was admitted to hospital with pelvic pain and nausea. A large mass filling the whole pelvic cavity was detected during physical and radiological examinations. Serum CA-125 level was detected as $561 \mathrm{U} /$ $\mathrm{mL}$ whilst the other tumour markers were within normal limits including HE4. A peritoneal biopsy was taken and reported necrotizing granulomatous inflammation with caseifications (tuberculosis).

A correct preoperative diagnosis of female peritoneal tuberculosis is usually not possible through clinical findings and laboratory tests. Family and past history, physical examination, routine chest X-ray, ultrasonography and computer tomography (CT) evaluation may not be specific enough for the diagnosis of peritoneal tuberculosis (1). Laboratory studies to diagnose peritoneal tuberculosis such as isolated mycobacteria, an ascitic adenosinedeaminase (ADA) test and a tuberculin skin test are usually ineffective for diagnosing peritoneal tuberculosis. Patients who present with a pelvic mass, ascites and increased CA-125 level must be considered as ovarian cancer in the differential diagnosis until proven otherwise. Suspicion about peritoneal tuberculosis is a must to conclude diagnosis without any laparotomy or laparoscopy, which emphasizes the importance of and need for new markers. Serum CA-125 level can increase both in benign and malign diseases (4). HE4, which has been proven to be a reliable marker specific to ovaries and epididymis, is not influenced by peritoneal diseases. The employment of HE4 tumour markers not only increases the sensitivity and specificity of the diagnosis of ovarian tumours but also differentiates benign diseases such as peritoneal tuberculosis that may be suspected, especially in young patients with normal levels of HE4.

Ethics Committee Approval: Ethics committee approval was received for this report from the ethics committee of Zeynep Kamil Hospital.

Informed Consent: Written informed consent was obtained from the patients for the publication of this case report.

Peer-review: Externally peer-reviewed. 
Author contributions: Concept - C.K, A.K., Z.N.D.; Design - Z.N.D., A.K., C.K.; Supervision - A.K., Z.N.D., C.K.; Resource - Z.N.D.; Materials - Z.N.D., A.K., A.T.; Data Collection\&/or Processing - Z.N.D., A.T., C.K.; Analysis\&/or Interpretation - Z.N.D., C.K., A.K., A.T.; Literature Search Z.N.D., C.K.; Writing - C.K., Z.N.D., A.T., A.K.; Critical Reviews - C.K., Z.N.D., A.K., A.T.

Acknowledgements: The authors sincerely thank Fujirebio Diagnostics Inc. Göteborg, Sweeden. HE 4 and CA-125 kits were provided by Fujirebio Diagnostics Inc.

Conflict of Interest: Fujirebio Diagnostics had provided HE4 and CA 125 kits for free as a grant.

Financial Disclosure: The authors declared that this report has received no other financial support.

\section{REFERENCES}

1. Gurbuz A, Karateke A, Kabaca C, Kir G, Cetingoz E. Peritoneal tuberculosis simulating advanced ovarian carcinoma: Is clinical impression sufficient to administer neoadjuvant chemotherapy for advanced ovarian cancer? Int J Gynecol Cancer 2006;(16 Suppl 1):307-12. [CrossRef]

2. Drapkin R, von Horsten HH, Lin Y, Mok SC, Crum CP, Welch WR, et al. Human epididymis protein 4 (HE4) is a secreted glycoprotein that is overexpressed by serous and endometrioid ovarian carcinomas. Cancer Res 2005;65:2162-9. [CrossRef]

3. Huhtinen K, Suvitie P, Hiissa J, Junnilla J, Huvila J, Kujari H, et al. Serum HE4 concentration differentiates malignant ovarian tumours from ovarian endometriotic cysts. Br J Cancer 2009;100:1315-9. [CrossRef]

4. Soper JT, Hunter VJ, Daly L, Tanner M, Creasman WT, Bast RC Jr. Preoperative serum tumor-associated antigen levels in women with pelvic masses. Obstet Gynecol 1990;75:249-54. 